\title{
Medical Students' preferences in Using Various Learning Resources for Physiology
}

\author{
Bhimani, N. ${ }^{1}$, Kowale, A.N. ${ }^{2}$
}

\begin{abstract}
Background: The number of resources available and accessible to medical students studying a Physiology in their phase 1 of M.B.B.S. is growing in leaps and bounds. Apart from traditional learning resources such as lectures and textbooks, students are increasingly using e-learning tools to learn Physiology. The students' preference for learning resources has not been studied in detail in any Indian settings. The deeper and better understanding of the tools used by students for learning medical Physiology could provide useful information to medical educators when designing and implementing Physiology curriculum for medical students.

Methods: 200 first M.B.B.S students were invited to complete an online survey. Questions asked were pertaining to students' frequency of using different types of resources when learning Physiology in first year of M.B.B.S.

Results: 192/200 (92\%) of students completed the survey, with the respondent age between $17-19$ years. The gender distribution was even, with male $(n=93,46.50 \%)$ and female $(n=99,54.50 \%)$ students responding to the survey. The students preferred to attend practical classes (RII $=0.95)$, read textbooks for learning a topic $(R I I=0.91)$, attend a lecture class $(R I I=0.85)$ and attend a small group discussion (RII = 0.81).

Conclusion: Inspite of increase in e-learning resources, traditional resources like attendance in practical classes, reading textbooks for learning a topic, attendance in lecture class and attendance small group discussion for learning Physiology are preferred ways by the students.
\end{abstract}

Keywords: E-learning, Learning resources, Physiology, Medical

\section{Background}

Recently, there is exponential growth in availability of educational resources availability to medical students. Apart from age old resources like lectures, textbooks and tutorials, students have access to mobile technology and online tools for learning (Davies 2012), which are referred to as e- learning tools. The concept of blended learning, which is admixture of elearning and traditional learning tools, is well recognised (Ruiz,2006). The students' preference for learning resources has not been studied in detail in any Indian settings. The deeper and better understanding of the tools used by students for learning medical Physiology could

\footnotetext{
${ }^{1}$ Associate Professor, Department of Physiology, Lokmanya Tilak Municipal Medical College Mumbai ${ }^{2}$ Professor, Department of Physiology, B.J Medical College Pune.
}

Corresponding author: Noorin Bhimani drnoorin@gmail.com provide useful information to medical educators when designing and implementing Physiology curriculum for medical students. This study is designed to assess today's medical students' preference for educational resources for studying Physiology in first M.B.B.S.

\section{Methods}

Study context: The study was conducted in January 2020 at Lokmanya Tilak Municipal Medical College, Sion, Mumbai. The college offers four and half years M.B.B.S. course followed by one-year internship under Maharashtra University of Health Sciences.

Participants: All $(n=200)$ first year medical students from Lokmanya Tilak Municipal Medical College, Sion, Mumbai were send online questionnaire through Google form.

Data collection: The students were invited to participate in the study. Three reminders were then sent at two-week intervals and the survey was closed after a total of six weeks. No remittance or reward was offered to students for 
participating in the study. The survey was adopted from study (Wynter, 2019). The students were asked to identify, on a 5-point Likert scale (never, rarely, sometimes, often, always), to what extent resources were used for learning Physiology, with a list of 17 options, ranging from traditional methods of learning to e-learning platforms and apps.

Statistical analysis: Survey scales employed ordinal measures of self-reported use of resources $($ Never $=1$, Rarely $=2$, Sometimes $=$ 3 , Often $=5$, Always $=6$ ). A relative importance index was employed to assess to find preference for a particular resource. Mann Whitney $U$ test was employed to find the differences whether any gender differences exists in preference of the resources used for learning. A Principal Components Analysis was undertaken to investigate whether clusters exist within students' preference for resources.

\section{Results}

Demographics: In total, 192/200 (92\%) of students completed the survey, with the respondent age between $17-19$ years. The gender distribution was even, with male $(n=93$, $46.50 \%)$ and female $(n=99,54.50 \%)$ students responding to the survey.

Calculation of relative importance index $(\mathrm{RII})=$ $\mathrm{RII}=\mathrm{SW} /(\mathrm{A} \times \mathrm{N})$ where $\mathrm{W}=$ Weightage given to each factor by the respondents $A=$ Highest weight (i.e., 5 in this case) $\mathrm{N}=$ the total number of respondents.

RRI revealed that attending practical classes, reading textbooks for learning a topic, attending a lecture class, attending a small group discussion, watching online/YouTube video tutorial for learning a topic, taking written notes from the lecture classes, making written notes for the topic learning and reading the ebook on the mobile are more popular way of learning Physiology.

Mann Whitney $U$ test did not find any gender in male and females for any of inquired resources used for learning Physiology.

A principal component analysis (PCA) was undertaken to assess whether particular preferences for resources showed clustering. 17 items were included in the analysis, suitability of the data was confirmed with Kaiser-Meyer-Olkin test (0.802) and Bartlett's Test of Sphericity $(p<0.001)$. PCA revealed the presence of four components with Eigen Values above the recommended cut off point of 1 , however the inspection of the scree plot revealed only two of the factors to be above the clear break point. The two retained components account for $29 \%$ of the variance in the data; component 1 contributing to $15 \%$ and component 2 to $14 \%$ of the variance. Oblim rotation technique produced a solution with strong loading by most of the items loading to only one of the components and a correlation effect between the two components $(r=0.57)$. As illustrated in Table 1, PCA also revealed clustering occurred along the on-line and offline differentiation of resources with component one containing online and offline resources and component 2 containing off-line resource.

\section{Discussion}

This study sought to explore today's medical students' use of educational resources for learning medical Physiology in first M.B.B.S. Most of the students reported using online and offline resources for learning Physiology. Results indicate that attending practical classes, reading textbooks for learning a topic, attending a lecture class, attending a small group discussion, watching online/YouTube video tutorial for learning a topic, taking written notes from the lecture classes, making written notes for the topic learning and reading the ebook on the mobile are more popular way of learning Physiology. As against watching video or animation provided with the textbook, using a mobile app for learning a topic, reading Question-Answer type books for learning a topic, reading ebook online, using online question bank or quiz, collecting PowerPoint slides from teachers, reading the medical journal online and reading medical journals from the library have lesser uptake resources for learning. Traditional resources such as attending lectures in person, making written notes and reading textbooks remain, the most utilized resources for learning Physiology amongst first M.B.B.S. students.

The study did not find any gender differences in uptake of various resources for learning Physiology while other studies have reported a gender bias in student preference for learning styles. Mehmood et al. studied the personality traits and gender of medical students and found that men were significantly more 'impulsive sensation seeking', (Mehmood 2013).

The study found that the uptake of online learning resources which are for self-directed learning was less. The preferences for teacher centered approach was observed. This calls for think how we can encourage student centric and technology aided learning. Technology in 
medical education is now important (Masters 2016). The technologies have been incorporated in to our everyday social, emotional and professional lives. The technology can be effectively used by students in medical college. It is a point of profound ponderance why such techno savvy generation have less preference to mobile technology aided learning.

The study was a quantitative study, and use of qualitative or mixed method approach may have provided a deeper understanding of students' responses. The study may be repeated over many batches may give deeper insights and trends over years in usage of various resources to learn Physiology.

\section{Conclusion}

This study sought to gain a better insight of medical students' preferences for use various available resources for learning Physiology in first M.B.B.S. Inspite of increase in e-learning resources, traditional resources like attendance in practical classes, reading textbooks for learning a topic, attendance in lecture class and attendance small group discussion for learning Physiology are preferred ways by the students. Though students are using online resources and other means of learning, traditional method remains the mainstay for them. An increased understanding of students' preferences will help Physiologists in design and implementation of medical Physiology curriculum that is aligned to the needs of the students.

\section{References}

Davies, B.S., Rafique, J., Vincent, T.R., Fairclough, J., Packer, M.H., Vincent, R. and Haq, I., 2012. Mobile Medical Education (MoMEd)-how mobile information resources contribute to learning for undergraduate clinical students-a mixed methods study. BMC medical education, 12(1), pp.1-11.

Mehmood, S.I., Khan, M.A., Walsh, K.M. and Borleffs, J.C., 2013. Personality types and specialist choices in medical students. Medical teacher, 35(1), pp.63-68.

Masters, K., Ellaway, R.H., Topps, D., Archibald, D. and Hogue, R.J., 2016. Mobile technologies in medical education: AMEE Guide No. 105. Medical teacher, 38(6), pp.537-549.

Ruiz, J.G., Mintzer, M.J. and Leipzig, R.M., 2006. The impact of e-learning in medical education. Academic medicine, 81(3), pp.207-212.

Wynter, L., Burgess, A., Kalman, E., Heron, J.E. and Bleasel, J., 2019. Medical students: what educational resources are they using?. BMC medical education, 19(1), p.36. 